\title{
Discussion on the Promotion Strategies for Job Satisfaction of Teachers in Private Universities
}

\author{
Guangming $\mathrm{He}^{1, \mathrm{a}}$, Wensheng $\mathrm{Wu}^{2, \mathrm{~b}}$, Wang Zheng ${ }^{3, \mathrm{c}}$ \\ ${ }^{1,2,3}$ Changsha Medical University, Changsha,410219, Hunan \\ a email, ${ }^{b}$ email, ${ }^{c}$ email
}

Keywords: Teachers In Private University, Job Satisfacion, Promotiong Strategy

\begin{abstract}
Design the questionnaire of 'Job Satisfaction of Teachers in Private Universities', choose the teachers in three private universities of one province in south central China as the respondents and use the statistical software SPSS17.0 to do statistics and analysis. The results show that the overall degree of job satisfaction of teachers in private universities is lower, at the same time, teachers'degree of satisfaction for management system, job itself, scientific research condition, teachers' professional development, salary and welfare etc. is not high. The strategies of promoting job satisfaction of teachers in private universitiesinclude improving teachers' salary and welfare, improving teachers' academic research condition, increasing opportunity for teachers' participation in management, innovating the system of promotion and further education for teachers and improving the matching degree of people - position and people - organization.
\end{abstract}

\section{Introduction}

The earliest origin of job satisfaction is from Mayo's(1) Hawthorne Experiment. The scholar Hoppock(2) (1935) who is the first man putting forward the concept of Job Satisfaction, thinks that job satisfaction refers to the employee's satisfaction feeling to the environment factors in two aspects of psychology and physiology, that is the employee's subjective reflection of working situation. Job satisfaction of teachers in private universities is the overall feeling and opinion of teachers in private universities on their job, career, working conditions and working situation. As teachers' job satisfaction is closely related to teachers' job enthusiam and job performance etc., it not only attract the attention of managers in colleges and universities, but also catch the researcher's attention. In this paper, on the basis of the reference to the correlational studies of Minnesota questionnaire (MSQ), ‘Scale Table for Teacher’s Job Satisfaction’ made by Yunying Chen, Shaobang Sun(3) and Miguel Padilla(4), it makes 'Questionnaire of Job Satisfication of Teachers in Private Universities 'and divides the factors influencing teachers' job satisfication into seven factorial dimensions: job itself, job environment, salary and welfare, professional development, management and system, interpersonal relationship and school atmosphere.Chose the teachers in three private universities of one province in south central China as the respondents, sent out 300 pieces of questionnaire, and recycled 296 pieces with the recovery rate of $98.7 \%$. Use the statistical software SPSS17.0 to take scan statistic and analysis and we find that, the overall degree of job satisfaction of teachers in private universities is lower, and some teachers'degree of satisfaction for salary and welfare, scientific research condition, management system and teachers' professional development etc. is not high.So in order to promote teachers' job satisfaction, we should start from the following aspects. 


\section{Increase Teachers' Salary and Welfare}

Both the Hierarchy of Needs Theory(5) of Maslow and ERG Theory (6) of Alderfer think that, people have the low level of needs for clothing,food, shelter and transportation, and salary and welfare are the main channel for meeting the basic needs of teachers in private universities. Meanwhile in Two-factor Theory(7), it also thinks that salary and welfare belong to the 'hygiene factors', the 'health factors' need to gets improvement although it cannot improve the employees' satisfaction degree, but if it does not get improvement, it will lead to dissatisfaction. The survey result shows that, the satisfaction degree of some teachers on salary and welfare is low. Therefore, in order to to eliminate the dissatisfaction of teachers in private universities, we must improve teachers' salary and welfare. Firstly, we need to increase the salary and welfare of teachers in private universities from the aspect of absolute amount to meet the basic needs of teachers in private universities; Secondly, we have to change the distribution pattern that taking title and qualification as the center, and then make the salary and welfare become one motivation of stimulating teachers to devote themselve to education; Thirdly, on the basis of individual technology, knowledge and ability, to build an expected salary and welfare system which guarantees that the employee can reach to the ability standard to make the salary and welfare be more equitable and have more stimulating effects.

\section{Improve Teachers’ Academic and Scientific Research Conditions}

Both the Hierarchy of Needs Theory of Maslow and ERG Theory of Alderfer also think that, people not only have the low level of needs for clothing,food, shelter and transportation, but also have the high level of needs for meeting respect and self-realization or self-growth. The Two-factor theory also thinks that, in order to fully exploit teachers' potential for work, inspire teachers' lasting work enthusiasm and improve their job satisfaction, we have to start from the incentive aspects of making the job be rich of sense of accomplishment, making the job performance be approved and making the job itself be challenging. Academic research is the important carrier of making the teachers in private universities win others' respect, realize self-worth and realize self-growth, which is full of challenge. In this aspect, any results obtained can bring teachers a great sense of honor and pride. However, the survey data shows that the vast majority of teachers feel 'dissatisfaction' for scientific research conditions, which undoubtedly leads to the losing of motivation for teachers. Therefore, in order to promote the satisfaction degree of teachers in private universities, we must improve the scientific research conditions. Firstly, we should increase the funds investment on scientific research and actively strive for the increase of appropriation from relevant government departments to the scientific research work in private universities so as to provide material guarantee for the smooth carrying out of scientific research works; Secondly, we should increase the strength of scientific research management, and create conditions for teachers' scientific research work from the aspect of perfecting of scientific research management system. We should not only perfect the scientific research evaluation system, strengthen the management and supervision function of scientific research institutions, but also strengthen the scientific research result management, pay attention to the timely transformation and development of what has been completed or what has been identified and occupy the market with the fastest speed to produce benefit and provide service for teaching and teachers.

\section{Increase Opportunity of Participation and Management for Teachers}

The Hierarchy of Needs Theory of Maslow thinks that human have the need of self-actualization. MacGregor(8) also thinks that under the appropriate condition, adopting participative management and 
encouraging people to bring creativity into the organization's goals so as to make people have the right to speak on the decision-making of things related to themselves, which provides the opportunity of meeting their social needs and self-actualization needs. When the employee's social needs and self-actualization needs are met, the employees' enthusiasm will be higher, so did their loyalty to the organization, the productivity level and the degree of job satisfaction. Participating in management, as one of the important ways of meeting the high-level need of achieving self-worth for teachers in private universities, besides, the private universities should actively create conditions to let the teachers share the school's decision-making right, meet the need of teachers' self-actualization and increase the job satisfaction; Next, it is necessary to perfect the system of suggestion, enhance teachers' sense of participation and self-efficacy, improve the teachers' sense of loyalty and belonging to the school and promote the job satisfaction.

\section{Innovate the System of Promotion and Further Education for Teachers}

Equity Theory thinks that the personal satisfaction degree on job is decided by the individual perception on the balance of work efforts and work results. If the person perceive the fairness, then he or she will be satisfied, on the contrary, will be not satisfied. In work, the individual will intentionally or unintentionally compare themselves with others, and compare their giving and obtains with others, that is the horizontal comparison. If the ratio is relatively near, they will feel satisfied, on the contrary, they will not feel satisfied for the unfairness. The results obtained not only refers to what in physical level, but also includes the opportunities of personal promotion and further education. Individual promotion can bring personal growth opportunities, more responsibility and higher social status, besides, further education training can improve one's own knowledge structure, skill structure and ability structure and provide premise conditions for personal development. In the survey, the satisfaction degree of quite a number of teachers in private universities for the promotion and further education is not high. Therefore, in order to promote the job satisfaction of teachers in private universities, we have to perfect a fair and reasonable system of promotion and further education, which not only needs a fair result, but also needs a fair procedure.

\section{Improve the Matching Degree of People-Position and People-Organization}

People-position Matching Principle(10) refers to that the people's ability and the ability required by position exactly match, and this matching contains the concept of 'Just Right'; The correspondence of the two not only give play to people's ability to the best, make the result of work task to the best, but also can make the person have job satisfaction. Therefore, in order to promote the job satisfaction of teachers in private universities, we have to make people's ability and the ability required by position exactly match. People-organization Matching Theory(11) thinks that, a high matching degree of people-organization not only can improve employees' job satisfaction and organizational commitment, but also can improve the overall performance of the organization. So, in order to improve the matching degree of people-organization, first of all, we need to educate each teacher in private university to have a comprehensive understanding of our school's values, goals and norms. On that basis, stimulate their sense of identity and belonging and try our best to mix each teacher's personal values, goals and beliefs with the organization, besides, set their mental expectation of coexistence, common prosperity and co-creation, improve the matching degree with their school and enhance job satisfaction. Secondly, strengthening psychological test on teachers' disposition, temperament, attitude, ability and other aspects to understand 
their personality characteristics, and provide the work and position that match their personality characteristics to achieve the aim that people do what they can do and give full play to their ability on their position. Besides, the private universities should provide conditions of physical, economic, institutional and psychological that all the teachers need in the aspects of working conditions, housing conditions, scientific research conditions, salary, promotion and further education and academic innovation etc. tomake the teachers in private universities be enthusiastic in the work, and be willing to offer what they have learned, eventually complete the matching of people-organization and achieve the goal of mutual development of teacher individual and school.

It is undeniable that the above strategies have certain scientificity and feasibility, however, because of the difference of actual situations for private universities, it is more likely represented as a theoretical assumption. If we want to make it more operational, there's still a lot of work to do, which needs the constant study and exploration by the managers and researchers in private universities.

\section{Bibliography}

[1] Mayo. Human Problems of Industrial Civilization[M].Beijing:China Social Sciences Press,1994:50-55

[2] Hoppock. Job Satisfaction [R]. New York: Harper \& Brothers Publishers, 1935: 8-21

[3] Yunying Chen, Shaobang Sun, Measurement Study of Teachers’ Job Satisfaction[J].Psychological Science.1994(5):146-149

[4] Miguel Padilla, Xinshui Xie etc. Influences and Promotion Strategies for Job Satisfaction of Teachers in American Public Universities--Investigation of One American Research-type Public University in the Background of Financial Crisis[J].Education Management in Universities.2014(5):70-79

[5] Maslow, A. , H. , Stephens, D. C. , \& Heil, G. Maslow on management[M]. New York: Wiley, 1998

[6] Alderfer, C. P. Existence, Relatedness, and growth[M]. New York: Free Press, 1972

[7] Herzberg,F. Mausner, B. Synderman,B,B. The Motivation to Work[M].3rd edition, Transaction Publishers, New Brunswick, New lersey, 1999, 85-92

[8] Fred Luthans.Organizational Behavior[M]. Wang Lei(Translator).Beijing:Posts and Telecom Press,2003(8):160-163

[9] Adams, J. S. Inequity in social exchange[J]. In L. Berkowitz (Ed. ), Advances in experimental Social psychology. New York: Acaemic Press. 1965, Vol. 2, 267-299

[10] Yanghua Jin, Chongming Wang. Research Development and Significance of People-organization Matching[J].Human Working Efficiency,2001,(2)

[11] Kristof,A.L. Person-organization fit: An integrative review of its conceptualizadons, measurement, and implications[J]. Personnel Psychology, 1996(49),1-30

\section{Date of Reception}

Fund Program--Hu’nan Province Education Department 2010 Hu’nan Institution of Higher Learning Science Research Projects 'Study of Current Situation and Countermeasures for Job Satisfaction of Teachers in Private Universities'(10C0440)

1 About the author:Guangming He(1975-), Leiyang,Hu'nan, teacher of Changsha Medical University, lecturer and PhD of Hunan University, Research Field: education management psychology, effectiveness of ideological and political education 
2 Corresponding author: Wang Zheng(1982-), Changsha, Hu’nan, teacher of Changsha Medical University, lecturer, master,Research Field: Teacher Management in Colleges and Universities 